\title{
PERCEPÇÃO DAS POLÍTICAS DE GESTÃO DE PESSOAS E COMPROMETIMENTO ORGANIZACIONAL EM UMA UNIVERSIDADE PÚBLICA
}

\author{
PERCEPTION OF PEOPLE MANAGEMENT POLICIES AND ORGANIZATIONAL COMMITMENT IN A \\ PUBLIC UNIVERSITY
}

\author{
CHARLIZE DA COSTA ANDRADE E LIMA \\ Núcleo de Pós-Graduação em Administração da Universidade Federal da Bahia (NPGA/UFBA) \\ Mestre e Doutoranda em Administração - NPGA/UFBA \\ Orcid: http://orcid.org/0000-0002-9849-9975 \\ E-mail: andrade.charlize@hotmail.com \\ Endereço: Av. Reitor Miguel Calmon, s/n - Vale do Canela \\ CEP 40.110-903 - Salvador - BA \\ DIVA ESTER OKAZAKI ROWE \\ Professora Associada no Núcleo de Pós-Graduação da Universidade Federal da Bahia (NPGA/UFBA) \\ Doutorado em Administração - NPGA/UFBA \\ Orcid: http://orcid.org/0000-0003-4760-5157 \\ E-mail: divarowe@gmail.com
}

\section{RESUMO}

O presente estudo teve como objetivo analisar as influências da percepção das políticas de gestão de pessoas no comprometimento organizacional de uma categoria peculiar de trabalhadores, docentes universitários, de uma universidade pública. Para tanto, foi realizado um survey que obteve a participação de 284 docentes. O instrumento utilizado na pesquisa foi composto por escalas que mensuraram o modelo tridimensional do comprometimento organizacional - afetivo, normativo e instrumental - e as percepções dos participantes acerca das políticas de gestão de pessoas da organização, especificamente: recrutamento e seleção; envolvimento; treinamento, desenvolvimento e educação; condições de trabalho; avaliação de desempenho e competências e recompensas. Os dados foram submetidos a análises descritivas, fatoriais e modelagens de equações estruturais. Os resultados apontam que apenas as políticas de envolvimento e treinamento, desenvolvimento e educação, influenciam o comprometimento organizacional dessa categoria. Indicando, portanto, a necessidade de uma maior atenção por parte dos gestores públicos em relação às outras políticas, também relevantes, para a melhoria do vínculo estabelecido entre indivíduo-organização.

Palavras-chave: Políticas de gestão de pessoas. Comprometimento organizacional. Docente. Universidade. Treinamento. 


\begin{abstract}
This study was aimed at analyzing the influence of the perception of people management policies on the organizational commitment of a specific class of works, the professors of a public institution of higher education. To do so, a survey was conducted involving the application of a questionnaire that had the participation of 284 professors. The instrument used in the research was composed of scales that measured the three-dimensional model of organizational commitment - affective, normative and instrumental - and participants' perceptions about the organization's people management policies, specifically: recruitment and selection; involvement; training, development and education; work conditions; performance evaluation and competencies and rewards. The data was submitted to descriptive, factorial and structural equation modeling analysis. The results show that only the policies of involvement and training, development and education, influence the organizational commitment of such category. Therefore, it indicates the need for a greater attention on the part of the public managers in relation to other policies, relevant as well, for the improvement of the bond between individualorganization.
\end{abstract}

Keywords: People Management Policies. Organizational Commitment. Professor. University. Training.

\title{
1 INTRODUÇÃO
}

O mundo tem sido palco de uma série de mudanças cada vez mais rápidas e intensas, que atingem os mais diversos entes sociais, como, por exemplo, as organizações. Essas transformações proporcionam ambientes de trabalho instáveis e exigem constantes ajustamentos por parte das organizações para garantirem a sua sobrevivência e/ou crescimento (BASTOS, 1993; LEITE et al., 2015). Dentre as estratégias adotadas nesse intuito, percebe-se uma especial atenção direcionada ao comprometimento dos indivíduos, contemporaneamente considerados como fontes de diferencial competitivo.

Estudos científicos têm demonstrado que o comprometimento não apenas contribui para melhores resultados organizacionais, como satisfação com o trabalho, redução de custos, queda na rotatividade e absenteísmo, mas também acarreta a melhoria de desempenho dos seus colaboradores (BASTOS; AGUIAR, 2015; MARIANO; MOSCON, 2018; ROMAN et al., 2012). No entanto, apesar das evidências positivas, ainda há controvérsias em torno de seu conceito, antecedentes e consequentes, assim como em relação à melhor maneira de gerenciá-lo (BASTOS et al., 2013). Diante dessa constatação, verifica-se que, apesar da falta de consenso que envolve vários aspectos do construto, a importância adquirida pelos indivíduos nas organizações é ponto pacífico entre os estudiosos da área.

Partindo da premissa de que o sucesso das organizações contemporâneas está diretamente relacionado à atuação dos indivíduos que a compõem, a área de gestão de pessoas adquiriu uma posição crucial na estrutura dessas organizações (ARRAES et al., 2017). Segundo Santos et al. (2016), houve uma ampliação da perspectiva de atuação dessa área, ou seja, aumentou, além da sua responsabilidade, o nível de cobrança e expectativa de retorno a partir de uma postura mais dinâmica e estratégica (BORGES; MARQUES; ADORNO, 2005). Adicionalmente a esta questão, Demo (2010) e Arraes et al. (2017) ressaltam a importância da 
implementação de políticas de gestão de pessoas que preconizem a valorização de seus trabalhadores.

Para delinear a presente pesquisa foram consideradas algumas lacunas de estudos, apontadas por diversos autores, sobre as temáticas em voga. Entre estes, Ventura (2012) aponta a necessidade de ampliar os estudos que buscam relacionar os construtos gestão estratégica de pessoas, comprometimento organizacional e ensino superior, levando em consideração diferentes instituições no Brasil e no exterior. Horta, Demo e Roure (2012) alertam que são pertinentes a realização de pesquisas que relacionem políticas e práticas de gestão de pessoas a outras variáveis do comportamento organizacional, combinando, inclusive, diferentes perspectivas metodológicas para subsidiar uma análise mais consistente dos efeitos no bem-estar dos indivíduos e nos resultados organizacionais. Demo, Martins e Roure (2013) reforçam a importância de estabelecer relação entre variáveis multidisciplinares, como políticas de gestão de pessoas, comprometimento organizacional e satisfação no trabalho, por exemplo, em organizações públicas e do terceiro setor. Ventura e Leite (2014) salientam que os construtos "comprometimento organizacional" e "gestão estratégica de pessoas", quando associados, podem agregar informações relevantes aos estudos nacionais e internacionais na área do comportamento humano nas organizações. Ademais, Lima e Rowe (2014), após mapear a produção científica brasileira, relacionando comprometimento organizacional e gestão de pessoas, identificam uma carência de publicações envolvendo esses dois construtos. 0 mapeamento identificou que os estudos nacionais privilegiam as políticas de desempenho e de qualidade de vida no trabalho, não averiguando, simultaneamente, diferentes políticas de gestão de pessoas com o comprometimento organizacional.

Além desses aspectos, Rowe, Bastos e Pinho (2013) ressaltam a carência de publicações nacionais e do exterior sobre comprometimento no trabalho entre docentes, em especial, do ensino superior. No contexto nacional, dentre os estudos com esse recorte, encontram-se os de Costa, Chiuzi e Dutra (2013) e Ribeiro Filho e Honório (2014). Ainda no que concerne ao construto comprometimento, especificamente nos seus instrumentos de medição, Jesus e Rowe (2017) sinalizam a importância da aplicação da Escala de Sacrifícios Percebidos (instrumental), relacionando-a com variáveis antecedentes, como políticas de gestão de pessoas.

Sendo assim, além das lacunas identificadas na literatura, constata-se que outros fatores justificam o desenho conceitual e metodológico da presente investigação. A Universidade Federal da Bahia (UFBA) foi escolhida por se tratar de uma instituição pública de ensino superior, reconhecida nacional e internacionalmente, que desempenha um papel de grande relevância social, uma vez que prima pela produção, socialização e ampliação do conhecimento e também pela escassez de investigações que contemplem os temas explorados neste estudo na referida instituição. Além disso, a UFBA vivenciou um processo de reestruturação com a implementação da Universidade Nova e adesão ao Programa de Apoio a Planos de Expansão e Reestruturação das Universidades Federais (REUNI), o que resultou na sua expansão. A mesma possui, hoje, 33 unidades universitárias divididas em escolas, faculdades e institutos.

No que tange à opção pela categoria docente do ensino superior, as razões foram pautadas nas características que envolvem a sua realidade, a complexidade e a diversidade de atividades, tais como submissão a diferentes regimes de trabalho, possibilidades de atuação em diferentes instituições, condições de trabalho variadas, atuação no ensino, na extensão, na gestão, na formação de recursos humanos, com orientações, e na pesquisa; e avaliações 
constantes de seu desempenho profissional. Em virtude dessas peculiaridades, trabalhos recentes como o de Irigaray et al. (2019) e o de Polizzi Filho e Claro (2019) tiveram docentes do ensino superior como sujeitos de pesquisa, sendo que o primeiro investigou as variáveis sentido e vínculos do trabalho, enquanto o segundo, abordou as variáveis intenção de rotatividade, bemestar no trabalho e capital psicológico, ambos aplicados em universidades privadas.

Diante do exposto, chegou-se a seguinte questão de pesquisa: qual a influência da percepção das políticas de gestão de pessoas no comprometimento organizacional dos docentes da UFBA? Dessa maneira, a presente investigação se propõe a analisar a influência das políticas de gestão de pessoas no comprometimento organizacional entre docentes da UFBA. Vale ressaltar que os resultados poderão contribuir para o enriquecimento das discussões acadêmicas e avanços deste campo de estudo e, também, servir de parâmetro para os gestores, não só da organização alvo, reavaliarem, aprimorarem e/ou desenvolverem ações efetivas para a manutenção ou melhoria do comprometimento estabelecido entre indivíduos e organização.

O estudo está estruturado da seguinte maneira: uma seção introdutória, seguida do referencial teórico, discutindo comprometimento organizacional e gestão de pessoas; posteriormente, é apresentada a metodologia, seguida da seção de resultados e conclusão.

\section{REFERENCIAL TEÓRICO}

Nesta seção são apresentados os temas abordados no estudo: comprometimento organizacional e gestão de pessoas, essenciais para o alcance dos objetivos estabelecidos.

\subsection{COMPROMETIMENTO ORGANIZACIONAL}

O comprometimento organizacional tem sido um dos construtos mais estudados ao longo das últimas décadas, nas mais diversas áreas do conhecimento. Segundo Siqueira e Gomide Jr. (2004), o seu caráter multidisciplinar desencadeou o surgimento de diversas concepções acerca do tema. Ainda em virtude dessa gama de abordagens relacionadas ao construto, Bastos e Aguiar (2015) afirmam não haver um consenso na literatura no que se refere à sua conceituação, assim como as propostas de mensuração também são bem variadas, dificultando o estabelecimento de definições claras e precisas sobre o fenômeno. A definição mais utilizada para o comprometimento organizacional é a do estado psicológico, que vincula o empregado à organização, implicando, assim, na decisão do empregado em permanecer ou não na organização (MEYER; ALLEN, 1991).

Na literatura, destaca-se o modelo tridimensional de Meyer e Allen (1991), que define três dimensões como componentes do comprometimento, a saber: afetiva, instrumental e normativa. Para esses autores, o desejo fundamenta a dimensão afetiva do comprometimento. Ou seja, há, no sujeito, a vontade de permanecer na organização. Já a necessidade é a base da dimensão instrumental, onde é avaliado o custo-benefício em se desligar da organização após certos investimentos pessoais e financeiros. Por fim, a obrigação moral, que caracteriza o comprometimento normativo, representa o sentimento de obrigação do indivíduo em permanecer na organização.

Ainda com relação ao modelo explicitado, é válido registrar que os indivíduos podem ter as três dimensões afetiva, normativa e instrumental ao mesmo tempo, podendo apresentar níveis diferenciados (BORGES; MARQUES; ADORNO, 2005; SIQUEIRA; GOMIDE JR., 2004). Rowe (2008) 
ressalta que, enquanto o comprometimento afetivo envolve ligações afetivas, os outros dois estilos de vínculos expressam dimensões cognitivas inerentes à relação entre trabalhador e organização.

A dimensão afetiva do comprometimento organizacional se apresenta por meio de sentimentos de afeto, apego e desejo de dispender esforços em prol da organização (LEITE; ALBUQUERQUE, 2011). No comprometimento afetivo, há uma identificação do indivíduo com os valores e objetivos da organização e, por esta razão, prevalece o desejo de manutenção do vínculo empregatício (SIQUEIRA; GOMIDE JR., 2004).

A dimensão instrumental do comprometimento envolve um processo avaliativo por parte dos trabalhadores, onde são considerados os ganhos e as perdas associadas ao desligamento da organização (ROMAN et al., 2012, SIQUEIRA; GOMIDE JR., 2004). Almeida (2009) esclarece que os indivíduos com alto comprometimento instrumental resistem a perder os investimentos que acumularam na organização e que têm a percepção de que muito dificilmente conseguirão substituir ou compensar em outro emprego, sinalizando que os custos associados à sua saída são demasiadamente grandes para que sejam consideradas outras alternativas. Salienta-se que os ganhos envolvidos nessa avaliação por parte do indivíduo não correspondem apenas aos financeiros, mas também aos ganhos intangíveis ou simbólicos (REIS NETO; MARQUES; PAIVA, 2017).

No que concerne à dimensão normativa, Siqueira e Gomide Jr. (2004) salientam que esse vínculo é composto por pensamentos nos quais são reconhecidas obrigações e deveres morais para com a organização, que são acompanhados ou revestidos de sentimento de culpa e inquietação quando o empregado cogita sair da organização. Nesse contexto, Roman et al. (2012) consideram que essa percepção de débito com a organização, está bastante relacionada com as crenças, valores e costumes dos indivíduos. Demo, Martins e Roure (2013) complementam que as organizações muitas vezes se utilizam de diferentes estratégias objetivando preservar essa crença nos seus colaboradores.

Vale registrar que, apesar da hegemonia conquistada pelo modelo conceitual proposto por Meyer e Allen (1991), estudiosos têm, mais recentemente, debatido sobre o caráter ambíguo e impreciso que envolve a amplitude do construto (BASTOS; AGUIAR, 2015), optando, assim, pela abordagem unidimensional do construto com foco na base afetiva, como ocorre, por exemplo, no estudo de Fernandes, Siqueira e Vieira (2014). Ainda assim, o modelo tridimensional continua predominando nas pesquisas nacionais e internacionais sobre comprometimento (SILVA; TOMAZZONI; COSTA, 2018).

Além dos trabalhos acadêmicos que buscam compreender definição e bases dos vínculos estabelecidos entre indivíduos e organização, percebe-se um interesse crescente nos fatores antecedentes, correlatos e consequentes do comprometimento (SOUZA; MARQUES, 2014). Para esses autores, os antecedentes do comprometimento organizacional se referem aos fatores que influenciam positivamente a ocorrência do comprometimento; os consequentes são os fatores considerados a partir do comprometimento ou não dos indivíduos, ou seja, os resultados provenientes da existência ou não do construto. Já os correlatos do comprometimento organizacional dizem respeito às variáveis que não podem ser consideradas antecedentes ou consequentes, mas estão fortemente associadas ao comprometimento organizacional, tais como motivação e satisfação no trabalho (BASTOS, 1993; BASTOS et al., 2013). Estudos como o de 
Bastos et al. (2013) e Demo, Martins e Roure (2013) apontam as políticas de gestão de pessoas como antecedentes do comprometimento organizacional. Diante disso, mostra-se relevante explorar a produção sobre as políticas de gestão de pessoas, uma vez que estas podem estimular o comprometimento dos indivíduos.

\subsection{GESTÃO DE PESSOAS}

As transformações que afetaram, ao longo dos últimos anos, o ambiente de trabalho, a economia, o contexto mercadológico e tecnológico, fizeram emergir a necessidade de uma gestão de pessoas capaz de conduzir às mudanças organizacionais (HENRIQUES et al., 2012). Diante desse panorama, pode-se inferir que a área de gestão de pessoas (GP) adquiriu uma relevância significativa na estrutura das organizações e, com isso, observou-se uma responsabilidade maior da mesma, atuando numa perspectiva mais gerencial, voltada para o envolvimento e a colaboração dos indivíduos (SANTOS et al., 2016). Nessa abordagem mais recente da GP, o indivíduo é concebido como crucial no processo de consecução dos objetivos organizacionais, tornando-se um elemento estratégico (DEMO; MARTINS; ROURE, 2013).

Nesse cenário competitivo e dinâmico, as organizações necessitam promover o desenvolvimento e o bem-estar dos indivíduos, utilizando-se de políticas que demonstrem o seu valor, já que há uma forte correlação entre a capacidade da organização ser competitiva e sua capacidade de reunir e produzir conhecimento, o que só é possível mediante a atuação dos seus funcionários (DEMO et al., 2012).

No que se refere às políticas de gestão de pessoas, a sua importância para as organizações pode ser percebida pela quantidade de estudos que vem sendo desenvolvidos, em diversos focos. Em algumas situações, os autores trabalham as políticas de gestão de pessoas de uma maneira geral (LEITE; ALBUQUERQUE, 2011, 2013; SILVA; LEITE; RODRIGUES, 2016; VENTURA; LEITE, 2014), em outras, são utilizadas políticas específicas, como por exemplo, remuneração e recompensas (OLIVEIRA et al., 2014; REIS NETO; MARQUES; PAIVA, 2017; RIBEIRO, 2008), treinamento (BALSAN et al., 2017; PILATI; BORGES-ANDRADE, 2005; SANTOS; MOURÃO, 2011; SOBRINHO; SILVA, 2015), qualidade de vida no trabalho (LÍRIO; SEVERO; GUIMARÃES, 2018; MILHOME; ROWE; SANTOS, 2018; SCHIRRMEISTER; LIMONGI-FRANÇA, 2012), avaliação de desempenho (SILVA et al., 2018), dentre outras. Nesse aspecto, vale destacar o estudo recente realizado por Tinti et al. (2017), que analisou o impacto das políticas e práticas de recursos humanos sobre os comportamentos de cidadania organizacional. Neste trabalho, os autores investigaram as políticas e práticas mencionadas como um construto único e, também, a relação de cada política separadamente com a variável dependente.

Demo et al. (2012), recorrendo a definições e pressupostos formulados por autores do exterior e ao próprio trabalho de Demo (2008), destacam as políticas de GP mais citadas na literatura. Dentre elas, os autores selecionam seis, a saber: recrutamento e seleção; envolvimento; treinamento, desenvolvimento e educação; condições de trabalho; avaliação de desempenho e competências e recompensas.

Demo e Nunes (2012, p. 36) diferenciam política de prática de gestão de pessoas. Consideram política de GP como sendo "habilidade no trato das relações humanas, com vistas à obtenção de resultados desejados" e as práticas no sentido de "hábito, rotina ou conjunto de ações ou atividades inseridas nas políticas". Dessa maneira, pode-se concluir que as políticas são compostas e se traduzem em uma série de práticas, o que justifica, inclusive, o uso apenas do 
termo políticas de GP no presente trabalho, uma vez que o mesmo contempla as duas dimensões envolvidas. Vale registrar que as políticas trabalhadas por esses autores foram utilizadas para o desenvolvimento desta pesquisa, pois as mesmas compõem a escala que foi utilizada na presente pesquisa para mensurar a percepção dos docentes da UFBA quanto às suas políticas de GP.

A seguir são apresentadas as definições das políticas de GP segundo Demo e Nunes (2012). Ressalta-se que todas as políticas são definidas como propostas articuladas da organização, com construções teóricas e práticas, mas com diferentes objetivos. A política de recrutamento e seleção busca procurar indivíduos, estimulá-los a se candidatar e selecioná-los, buscando harmonizar os valores, interesses, expectativas e competências da pessoa com as características e demandas do cargo e da organização. A política de envolvimento é definida para criar um vínculo afetivo com seus indivíduos, contribuindo para o seu bem-estar, em termos de reconhecimento, relacionamento, participação e comunicação. Já a política de treinamento, desenvolvimento e educação (TD\&E) procura prover aos indivíduos a aquisição sistemática de competências e estimular a contínua aprendizagem e produção de conhecimento. A política condições de trabalho tem como finalidade prover aos indivíduos boas condições de trabalho em termos de benefícios, saúde, segurança e tecnologia. A política de avaliação de desempenho e competências visa avaliar o desempenho e as competências dos indivíduos, subsidiando as decisões sobre promoções, planejamento de carreira e desenvolvimento. Por fim, a política de recompensas tem como pretensão recompensar o desempenho e as competências dos indivíduos em termos de remuneração e incentivos.

\section{PROCEDIMENTOS METOdOLÓGICOS}

Para atingir os objetivos do estudo, delineou-se uma pesquisa quantitativa, descritiva e explicativa. Tal classificação se justifica uma vez que as pesquisas descritivas visam apresentar as características de determinada população ou fenômeno ou estabelecimento de relações entre variáveis (GIL, 2010). Explicativa, por explicar o comprometimento organizacional a partir da GP.

A estratégia metodológica adotada, o survey, baseou-se na aplicação de questionário por e-mail com a utilização de um software de questionários online, o Survey Monkey, após o préteste. A escolha desta técnica se deve ao fato de os docentes terem uma familiaridade grande com a Internet, além de ser um recurso rápido e de baixo custo. Rowe (2008, p. 101) acrescenta que "(...) o participante do survey por e-mail pode ler e responder de acordo com sua conveniência. Isto pode aumentar a qualidade das respostas por dar ao respondente liberdade de pensar sobre suas propensões e opiniões.".

O instrumento de coleta de dados foi composto por itens fechados e estruturados em três segmentos, a saber: políticas de GP, comprometimento organizacional e dados pessoais e ocupacionais. Este último segmento buscou conhecer o perfil dos participantes referente a idade, sexo, estado civil, formação, última titulação, tipo de vínculo com a instituição, tempo de serviço, tempo de docência, unidade de lotação, regime de trabalho, nível e área de atuação e se possui cargo de chefia, assim como se tem vínculo anterior com a Universidade. Já os dois primeiros baseiam-se em diferentes escalas, especificadas a seguir.

Para mensurar a percepção de políticas de GP, foi utilizada a Escala de Políticas de Recursos Humanos (EPRH), desenvolvida e validada por Demo et al. (2012), que engloba seis fatores: recrutamento e seleção; envolvimento; treinamento, desenvolvimento \& educação; 
condições de trabalho; avaliação de desempenho e competências; e recompensas. A EPRH é formada por 40 itens que atendem às seis políticas mencionadas e visam aferir a percepção das políticas de gestão de pessoas de um determinado grupo de trabalhadores.

Para o estudo do comprometimento organizacional adotou-se as seguintes escalas: a escala de comprometimento instrumental revista por Powell e Meyer (2004) e traduzida, adaptada à cultura brasileira e validada por Jesus e Rowe $(2014,2017)$ e as escalas de comprometimento afetivo e normativo de Meyer, Allen e Smith (1993). Esse segmento foi formado por 18 itens, sendo seis de cada dimensão que integra o construto.

Os participantes foram convidados a responder manifestando o seu grau de concordância em relação a cada item, por meio de uma escala em formato tipo Likert de cinco pontos, variando de 1, discordo totalmente, a 5, concordo totalmente.

Após elaboração e inserção do questionário no Survey Monkey, foi realizado o pré-teste com um grupo de doze docentes de diferentes unidades da UFBA. Os critérios de escolha dos participantes do pré-teste foram: docentes com mais experiência em pesquisas, diferentes áreas de atuação e também, tempo de serviço diversificados. Uma vez analisados os resultados do préteste, não foram identificadas inconsistências e/ou observações relevantes que exigissem alterações significativas no instrumento.

O questionário foi enviado por e-mail aos docentes da UFBA. No e-mail foi encaminhado o link que direcionava o respondente para um questionário eletrônico depositado no software utilizado, o Survey Monkey e a sua participação estava condicionada a aceitação do Termo de Consentimento Livre e Esclarecido.

É válido registrar a impossibilidade de alcance de toda a população do presente estudo (composta por 2.257 docentes efetivos e 287 substitutos), pois, o acesso aos e-mails institucionais estava condicionado à disponibilidade dos mesmos no site da instituição. Diante da dificuldade encontrada em obter retorno, foi necessário realizar aplicação do questionário impresso e pessoalmente. Adicionalmente, recorreu-se à lista de e-mails dos docentes da UFBA.

Para tratamento e análise dos dados, os mesmos foram exportados para o Excel e realizada a limpeza do banco de dados, levando-se em consideração, por exemplo, os casos omissos (missing values). Além disso, foram inseridos manualmente na planilha os dados da aplicação pessoal dos questionários. Em seguida, os mesmos foram submetidos às análises estatísticas, norteadas pelos princípios definidos por Malhotra (2012) e Hair et al. (2009). Foram realizadas análises exploratórias dos dados, (avaliação da normalidade, outliers, linearidade e multicolinearidade), análise da qualidade da mensuração das escalas (dimensionalidade, confiabilidade e validade das medidas) e, por fim, adotou-se a técnica de modelagem de equações estruturais através do método de máxima verossimilhança.

Levando em consideração as peculiaridades do segmento ocupacional, alvo da investigação, docentes universitários, foram realizados testes das estruturas fatoriais das escalas e também indicadores de fidedignidade das medidas. A análise fatorial de cada escala foi realizada se recorrendo à extração dos fatores, o método dos componentes principais com eigenvalue maior que um e rotação oblíqua.

No presente estudo, a análise fatorial da escala de comprometimento organizacional resultou em 13 itens. Esta estrutura fatorial teve por base um valor de KMO (Kaiser-Meyer-Olkin) de 0,835 e teste de esfericidade de Bartlett com significância menor que 0,001, expressando, assim, a fatorabilidade da matriz de respostas ao questionário. Os três fatores explicam $54,583 \%$ 
da variância total. No que tange à confiabilidade dos itens, utilizou-se o cálculo do Alpha de Cronbach, que por fator, apresentam-se acima de 0,71.

$\mathrm{Na}$ análise fatorial da escala de políticas de recursos humanos se adotou os mesmos procedimentos aplicados na escala anterior, resultando em 17 itens distribuídos em cinco fatores, a saber: recrutamento e seleção; envolvimento; treinamento, desenvolvimento \& educação; avaliação de desempenho e competências, e; recompensas. Os resultados dos testes de adequação e esfericidade foram satisfatórios, sendo que o KMO apresentou um coeficiente de 0,909 e o teste de Bartlett apresentou resultado significativo menor que 0,001. Os cinco fatores da escala explicam $65,8 \%$ da variância total.

A amostra da pesquisa contou com 284 docentes, sendo 13 substitutos e 271 efetivos, de diferentes unidades de ensino que integram a UFBA. Vale registrar que, para compor a amostra do presente estudo, foram considerados os questionários cujas escalas estavam totalmente preenchidas, portanto, no que tange aos dados pessoais e ocupacionais, houve docentes que deixaram de respondê-los, parcial ou totalmente. Em virtude dessas abstenções, a seguir serão apresentados esses dados com base no percentual de respostas válidas para cada item. Entre os docentes participantes deste estudo, há uma predominância de homens (58,9\%); casados (58,6\%); a idade média é de 46 anos (houve participantes entre 25 e 69 anos de idade) e 75,7\% são doutores.

No que se refere ao tempo de docência e de serviço na instituição, os dados mostram que $34,7 \%$ dos participantes possuem até 10 anos de experiência em sala de aula e mais da metade $(55,1 \%)$ trabalham na UFBA a menos de 11 anos. Quanto ao regime de trabalho, há uma predominância de docentes com dedicação exclusiva $(79,1 \%)$ e que não possuem outro vínculo trabalhista (79,6\%). Ainda em relação às características ocupacionais, a amostra é composta por docentes que atuam nos quatro níveis de ensino (graduação, especialização, mestrado e doutorado), havendo uma predominância na Graduação. No que concerne à ocupação de cargo de chefia, $71,1 \%$ não estão exercendo cargo de liderança e 59,2\% possuem algum vínculo anterior com a instituição, sendo a maioria ex-aluno $(41,9 \%)$.

\section{APRESENTAÇÃO E DISCUSSÃO DOS RESULTADOS}

Em consonância com o objetivo central do presente estudo, apresentam-se os dados obtidos com o teste dos modelos de equações estruturais, cujo objetivo foi testar as influências da percepção das políticas de gestão de pessoas no comprometimento organizacional dos docentes da UFBA. Essa modalidade de análise foi utilizada, pois, segundo Pilati e Laros (2007), a modelagem de equações estruturais, além de permitir o teste confirmatório da estrutura psicométrica de escalas de medidas, viabiliza a análise das relações explicativas entre múltiplas variáveis simultaneamente, sejam essas latentes ou observadas.

No primeiro momento do processo, foi testado um modelo estrutural considerando as cinco dimensões das políticas de gestão de pessoas e as três bases do comprometimento organizacional. No entanto, possivelmente dado os desvios de normalidade e a amostra relativamente pequena para a quantidade de variáveis envolvidas, bem como a presença de multicolinearidade entre os construtos exógenos, foi observado que o modelo não convergia de forma apropriada, gerando variâncias de erros negativas e pesos padronizados fora dos limites aceitáveis. Desta maneira, adotou-se como alternativa dividir o modelo em três, um para cada 
variável dependente. Os modelos propostos apresentaram uma qualidade de ajuste aceitável com índices satisfatórios, conforme expresso na Tabela 1, demostrando, assim, a pertinência dos mesmos para explicar os construtos estudados.

Tabela 1- Índices da qualidade dos modelos propostos por variável dependente

\begin{tabular}{l|c|c|c}
\hline \multicolumn{1}{c|}{ Índices de Ajuste } & \multicolumn{3}{c}{ Modelos } \\
\cline { 2 - 4 } & $\mathbf{1}$ & $\mathbf{2}$ & $\mathbf{3}$ \\
\hline Qui-quadrado & 231,502 & 236,935 & 288,646 \\
\hline Índice de qualidade de ajuste - GFI & 0,927 & 0,925 & 0,915 \\
\hline Índice de ajuste comparativo - CFI & 0,961 & 0,959 & 0,956 \\
\hline Índice de ajuste normalizado - NFI & 0,893 & 0,892 & 0,879 \\
\hline Raiz do erro quadrático médio aproximado - RMSEA &, 042 &, 043 &, 042 \\
\hline
\end{tabular}

Notas: 1 - Comprometimento normativo, 2 -comprometimento afetivo, 3 -comprometimento instrumental.

Fonte: Dados da pesquisa.

Os resultados das modelagens de equações estruturais estão apresentados a seguir em sua forma sintética, objetivando melhor visualização e destaque para os aspectos que o presente estudo se propôs a examinar.

\subsection{MODELO DA INFLUÊNCIA DAS POLÍTICAS DE GESTÃO DE PESSOAS NO COMPROMETIMENTO NORMATIVO}

No Modelo 1, que testou as relações do comprometimento normativo com as variáveis antecedentes (políticas de GP), expresso na Figura 1, observa-se que a política de envolvimento influencia positiva e significativamente o comprometimento normativo, com aproximadamente $1 \%$ de significância e peso de 0,43. Ou seja, entre os docentes participantes do estudo, quanto mais percebem políticas de envolvimento na UFBA, como, por exemplo, um bom clima de confiança e cooperação entre os colegas de trabalho, maior se torna o comprometimento normativo com a universidade.

Figura 1- Modelo das Políticas de Gestão de Pessoas e Comprometimento Normativo

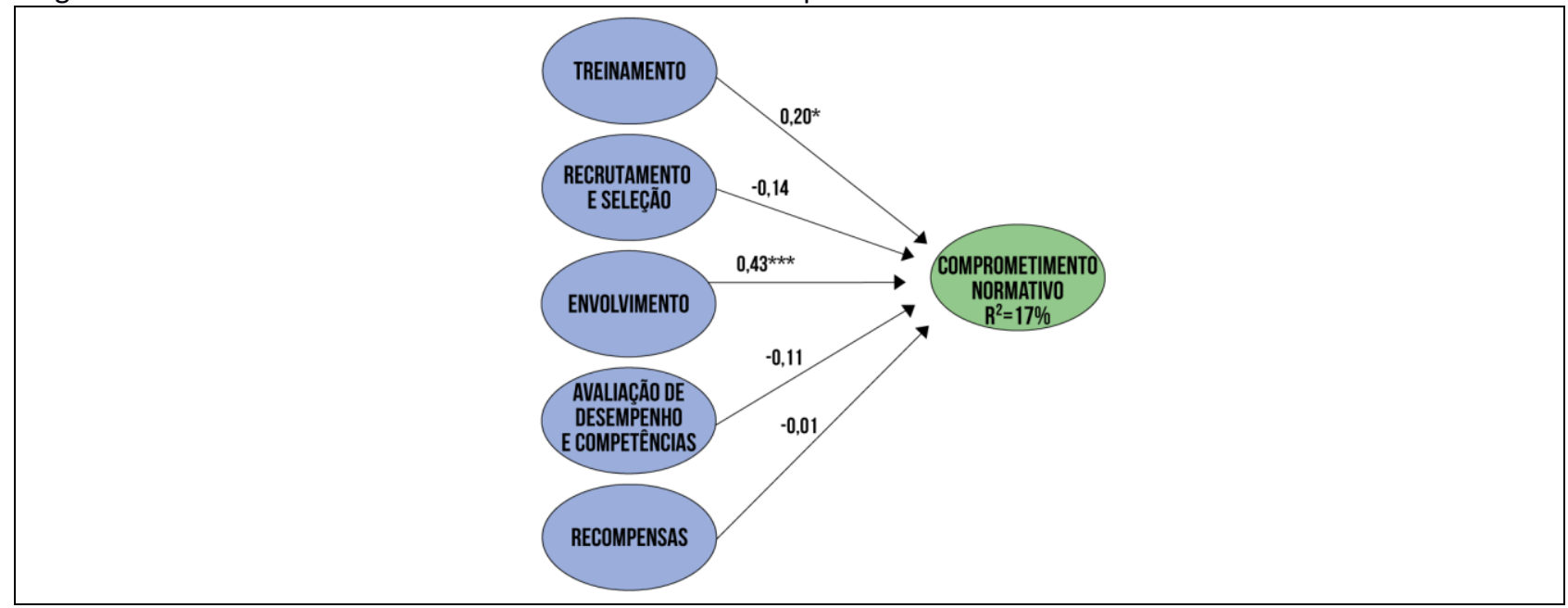

Legenda: ${ }^{*} \mathrm{p}<0,10 ;{ }^{* *} \mathrm{p}<0,05 ;{ }^{* * *} \mathrm{p}<0,01 ; * * * \mathrm{p}<0,001 ; \mathrm{O} \mathrm{R}^{2}$ corresponde ao percentual de variância explicada. Fonte: Dados da Pesquisa

Esse resultado atende à expectativa teórica, uma vez que a abordagem normativa se fundamenta na norma de reciprocidade, ou sentimento de dever, proveniente da internalização 
das normas organizacionais e da necessidade de retribuir o suporte recebido pela organização (BASTOS et al., 2013). Demo, Martins e Roure (2013) realizaram uma pesquisa, na qual a política de envolvimento foi considerada como uma das principais preditoras do comprometimento organizacional. No entanto, essas autoras ressaltaram a dimensão afetiva. Ainda no que se refere à política de envolvimento, vale salientar que um estudo realizado por Jesus (2016), com professores da carreira de Educação Básica Técnica e Tecnológica, apesar de não ter verificado influência direta das percepções das políticas de gestão de pessoas sobre o comprometimento dessa categoria ao longo do tempo, encontra resultado similar à presente investigação, ou seja, a pesquisadora identificou que a percepção da política de envolvimento se relacionou positiva e significativamente com o comprometimento normativo.

Faz-se pertinente ainda comparar os achados deste trabalho com os de Tinti et al. (2017), por se tratarem de estudos que abordam as relações das políticas de gestão de pessoas com construtos inerentes ao campo de estudos do comportamento organizacional, a saber: comprometimento organizacional e comportamentos de cidadania organizacional, respectivamente, ainda que direcionados a públicos diferenciados. Conforme apontado pela literatura, estes construtos, quando presentes na organização, tendem a trazer resultados benéficos para as mesmas (ANDRADE et al., 2017; BASTOS; AGUIAR, 2015; MARIANO; MOSCON, 2018; ROMAN et al., 2012). Nessa perspectiva de análise, os resultados encontrados pelos autores mencionados convergem com o presente estudo ao demonstrar que apenas a política de envolvimento apresenta relação significativa com comportamentos de cidadania organizacional.

Com o teste unicaudal foi possível identificar que a variável TD\&E (peso de 0,20) também apresenta um impacto positivo sobre o comprometimento normativo (conforme Figura 1). Sendo assim, entre os participantes da pesquisa, quanto mais percebem que a UFBA investe em seu TD\&E, propiciando seu crescimento pessoal e profissional de forma ampla, maior é o seu comprometimento normativo para com a universidade.

Em suma, as variáveis envolvimento e TD\&E explicam $17 \%$ do comprometimento normativo $\left(\mathrm{R}^{2}\right)$. Os índices de reajustes foram favoráveis com valores de $\mathrm{GFI}, \mathrm{CFI}, \mathrm{NFI}$ e outros índices próximos ou superiores a 0,91 e RMSEA abaixo de 0,05.

\subsection{MODELO DA INFLUÊNCIA DAS POLÍTICAS DE GESTÃO DE PESSOAS NO COMPROMETIMENTO AFETIVO}

No que tange ao segundo modelo, Figura 2, somente a dimensão envolvimento exerceu influência significativa e negativa no comprometimento afetivo, com peso de $-0,571$. Ou seja, quanto mais os docentes percebem as políticas de envolvimento, menos se comprometem afetivamente com a UFBA. Este resultado contradiz a literatura, pois era de se esperar que, quanto mais o docente se envolvesse com a UFBA, maior seria seu comprometimento afetivo. 0 estudo de Rowe, Bastos e Pinho (2013) também apresentou resultado similar, ao relacionar o comprometimento organizacional afetivo com desempenho.

Os resultados deste modelo deixam de evidenciar relação, por exemplo, do comprometimento afetivo com a política de TD\&E. Ainda com base em outros estudos, apesar de partir de outra perspectiva, foi demonstrado o caráter preditivo do comprometimento afetivo no interesse e impacto do treinamento no trabalho (PILATI; BORGES-ANDRADE, 2005; SANTOS FILHO; MOURÃO, 2011; BALSAN et al., 2017). 
Figura 2 - Modelo das Políticas de Gestão de Pessoas e Comprometimento Afetivo

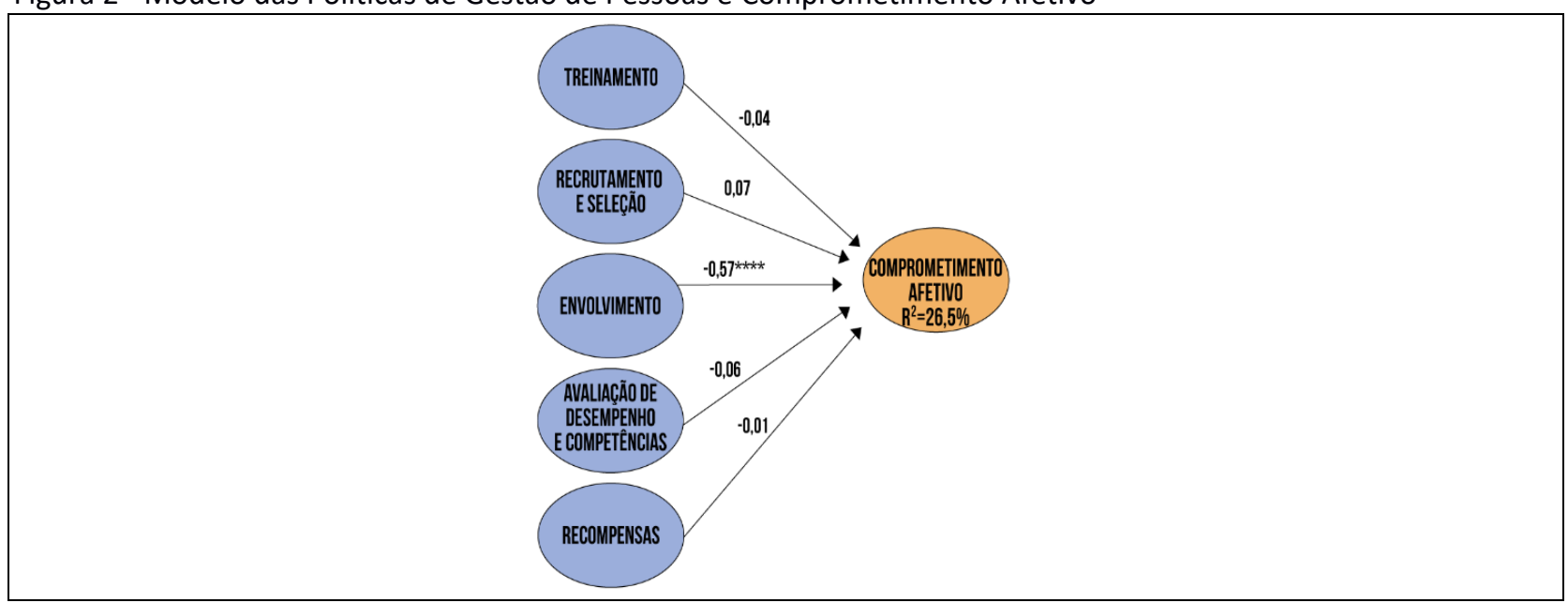

Legenda: ${ }^{*} p<0,10 ;{ }^{* *} p<0,05 ;{ }^{* * *} \mathrm{p}<0,01 ; * * * \mathrm{p}<0,001 ; O \mathrm{R}^{2}$ corresponde ao percentual de variância explicada. Fonte: Dados da Pesquisa

Vale registrar que, no modelo em estudo, o comprometimento afetivo foi explicado em 26,5\% dado o tamanho do coeficiente de determinação múltipla. Mais uma vez, os índices de ajuste foram favoráveis, demonstrando boa adequação do modelo aos dados. Esse resultado remete, mais uma vez, à pesquisa de Demo, Martins e Roure (2013), porém, no modelo em questão, a relação entre as variáveis se apresentou inversa.

\subsection{MODELO DA INFLUÊNCIA DAS POLÍTICAS DE GESTÃO DE PESSOAS NO COMPROMETIMENTO INSTRUMENTAL}

No Modelo 3, que examina as relações do comprometimento instrumental com as políticas de GP, expresso na Figura 3, nota-se que somente o construto TD\&E apresentou significância estatística com esse enfoque do comprometimento organizacional, revelando uma capacidade explicativa de $8 \%$, com peso de 0,255 . Os índices de ajustes também foram favoráveis. Esse resultado demonstra que, quanto mais os docentes da UFBA percebem as políticas de TD\&E, quanto mais a UFBA investe no treinamento, desenvolvimento e educação de seus docentes, como cursos, doutoramento, pós-doutorado, maior se torna o seu comprometimento instrumental com a organização.

Ponderando que, no comprometimento instrumental, os trabalhadores não avaliam apenas as perdas monetárias, mas também as intangíveis, como, por exemplo, oportunidades de aprendizagem e qualificação, pode-se inferir que, no caso dos docentes da UFBA, essa percepção justifique o estabelecimento da relação apresentada entre TD\&E e este tipo de vínculo com a organização estudada.

Ainda comparando com o estudo já citado, de Tinti et al. (2017), os resultados encontrados por esses autores para a política de treinamento e desenvolvimento vão de encontro ao exposto nesta pesquisa, uma vez que a mesma não manifestou impacto significativo sobre os comportamentos de cidadania organizacional dos docentes. Possivelmente, essa divergência de resultados emergiu por conta dos contextos diferenciados que caracterizam os lócus das pesquisas. 
Figura 3 - Modelo de Políticas de Gestão de Pessoas e Comprometimento Instrumental

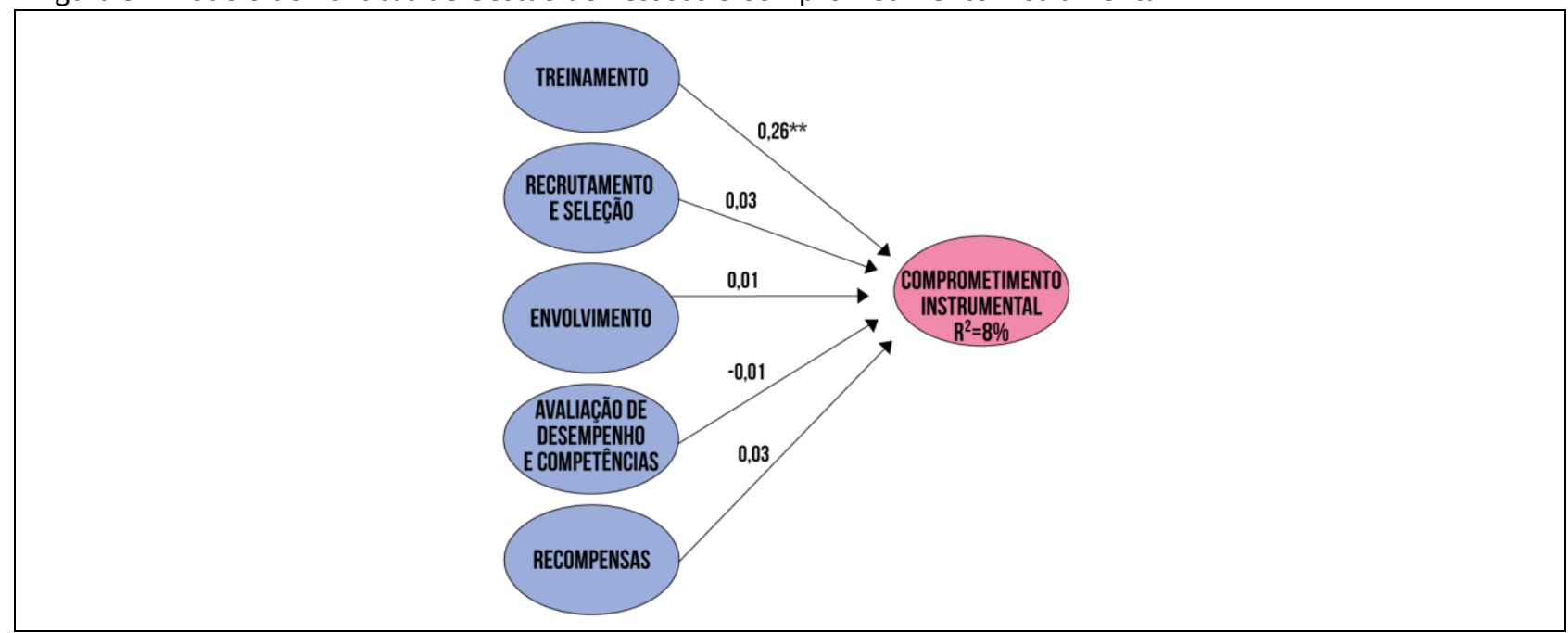

Legenda: ${ }^{*} p<0,10 ;{ }^{* *} p<0,05 ; * * * p<0,01 ; * * * * p<0,001 ; O R^{2}$ corresponde ao percentual de variância explicada. Fonte: Dados da Pesquisa

Segundo os resultados obtidos, constata-se que apenas duas políticas de gestão de pessoas, a saber, envolvimento e TD\&E, são percebidas de maneira a influenciar o comprometimento organizacional dos docentes da UFBA. No que tange à política de TD\&E, Bastos et al. (2013) afirmam que seus programas são, de maneira geral, favoráveis ao desenvolvimento do comprometimento, apesar de não ser esse o propósito principal. Segundo esses autores, esse impacto positivo pode ser intensificado, quando os indivíduos percebem que suas habilidades podem ser aproveitadas por esses programas e de que novas competências podem ser desenvolvidas.

Ressalta-se, porém, que as demais políticas, na percepção dos docentes participantes desta pesquisa não apresentaram influência significativa em nenhuma das bases do comprometimento. Portanto, é possível inferir que as práticas desenvolvidas pela UFBA, no que tange às políticas de avaliação de desempenho e competências, recrutamento e seleção e recompensas, não estão sendo percebidas pelos seus docentes e, portanto, merecem uma especial atenção por parte dos gestores. Em se tratando de uma organização pública brasileira, não se pode descartar como justificativa para tais achados o engessamento, por vezes imposto pela legislação que rege e regulamenta esses setores e categoria de trabalhadores.

No que se refere à política de recompensa, ainda que contemple segmentos distintos do ambiente educacional, cabe recorrer ao estudo de Costa, Chiuzi e Dutra (2013), cujos resultados apontaram que, para os professores de uma universidade privada de São Paulo, o fator salarial não é representativo quando se trata de empenho e dedicação adicionais em prol da organização. Se considerarmos o contexto das universidades públicas, onde a remuneração é conhecida desde o momento da seleção para ingresso no cargo, bem como a garantia da estabilidade no emprego e o conhecimento da remuneração ofertada pelo mercado, pode-se inferir que, por todas essas razões, a referida variável não se mostrou significativa em nenhuma das dimensões do comprometimento organizacional. Desta maneira, não se pode desprezar, na análise dos dados coletados, as particularidades que envolvem as organizações públicas e suas amarras legais. 


\section{CONSIDERAÇÕES FINAIS}

O presente estudo buscou contribuir com o conhecimento da influência da percepção de políticas de gestão de pessoas no comprometimento organizacional, atendeu ao objetivo da pesquisa. Entendendo como relevante o papel das pessoas e, portanto, da sua efetiva gestão nas organizações, estabelecer uma relação entre esses dois construtos representa uma contribuição considerável para a academia e, também, para as próprias organizações.

As universidades brasileiras, com o apoio e incentivos do governo federal, passaram por um processo grande de expansão, no qual foram ampliadas não só o número de vagas nos cursos de graduação, como também houve a reformulação dos seus currículos e, ainda, o aumento do seu quadro de pessoal. Na sequência, vem sofrendo com redução drástica de verbas. Dessa maneira, o estudo dessa categoria ocupacional, em plena fase de incerteza e cortes de investimentos na educação, mostra-se relevante e presume o surgimento de aspectos passíveis de novas investigações.

Os resultados do presente estudo evidenciaram que apenas as dimensões envolvimento e TD\&E exercem influência no comprometimento organizacional entre os docentes da UFBA, participantes desta pesquisa. Embora os achados não tenham demonstrado a influência das políticas de avaliação de desempenho e competências, recrutamento e seleção e recompensas no comprometimento dos docentes, a relação entre essas variáveis é promissora e, portanto, merecedora de mais investigações em outros contextos, principalmente se considerados estudos como, por exemplo, os de Ribeiro (2008) e Grohmann, Cunha e Silinske (2013) que enfatizam, respectivamente, a influência da percepção de uma justa remuneração no comprometimento e da relação preditiva do comprometimento no desempenho dos indivíduos.

Pelos dados apresentados na pesquisa, sugere-se que os gestores direcionem esforços no aprimoramento das práticas que contemplam, principalmente as políticas de avaliação de desempenho e competências, recrutamento e seleção e recompensas, visando melhorias no comprometimento organizacional dos docentes. No Brasil, o governo federal possui política de TD\&E para o docente universitário. Por exemplo, para a realização do pós-doutorado, há apoio financeiro que envolve a manutenção do salário e a possibilidade de ganhar bolsa, adicionalmente ao salário, além da possibilidade de até 12 meses de licença para dedicação ao pósdoutoramento. Também existem apoios para a realização de doutorado, para ser professor visitante em outro país. Levando em consideração a existência dessas iniciativas que estimulam a aprendizagem, o desenvolvimento de competências e a produção de conhecimento por parte do governo, pode-se inferir que para os docentes participantes desta pesquisa, quanto mais percebem positivamente as políticas de TD\&E, maior é o seu comprometimento com a UFBA. Nos últimos anos, o governo tem realizado um desinvestimento que tem atingido o pósdoutoramento e isso é preocupante, pois, conforme mostram os dados dessa pesquisa, quanto mais o docente tem a possibilidade de investir em sua capacitação, maior é o seu comprometimento com a sua universidade. Ou seja, a diminuição drástica de verbas para, por exemplo, o pós-doutoramento, atinge, de forma negativa, a produção científica brasileira, referente à quantidade e qualidade, e também impacta, de forma negativa, o comprometimento organizacional do docente.

Apesar das contribuições, essa investigação possui algumas limitações, tais como o tamanho da amostra, que inviabilizou um modelo de equações estruturais contendo os três 
fatores do comprometimento organizacional, o fato de analisar um contexto específico e, portanto, generalizações dos resultados não são pertinentes. Além desse aspecto, por se tratar de uma organização pública, há uma série de peculiaridades que envolvem o universo estudado e principalmente, na legislação que regulamenta a carreira docente. Outra limitação a ser considerada, se refere à escassez de estudos nacionais que trabalhem conjuntamente as diversas políticas de gestão de pessoas relacionando-as ao comprometimento, o que dificulta a comparação dos resultados da presente pesquisa com outros similares na literatura. Ademais, observa-se uma predominância de pesquisas que tratam da política de gestão de pessoas de uma maneira geral, ou seja, sem adentrar nas políticas específicas da área.

Dessa maneira, apresenta-se como sugestão para futuras pesquisas, a utilização de amostras de organizações de setores e naturezas diferentes, uma vez que segmentos diferenciados podem acarretar comportamentos distintos. Uma segunda opção seria replicar a proposta da presente pesquisa analisando e comparando diferentes categorias de professores (efetivos e substitutos, dedicação exclusiva e 20 horas), uma vez que esses vínculos distintos podem repercutir na maneira como esses profissionais percebem a gestão e a organização como um todo.

Outra sugestão para estudos futuros é a utilização de outras variáveis mediadoras entre os construtos estudados, como, por exemplo, percepção de justiça organizacional, tempo de trabalho na organização, tempo na carreira docente. Sugere-se também a aplicação deste estudo em outra instituição de ensino, a realização de estudos comparativos entre distintas instituições, já que diferentes culturas podem interferir nos resultados obtidos, ou, ainda, investigar outros fatores que possam influenciar o comprometimento organizacional dessa categoria de trabalhadores. Sugere-se, também, a utilização de outras abordagens metodológicas, como, por exemplo, estudos qualitativos ou qualitativos e quantitativos que viabilizem uma maior compreensão das relações aqui trabalhadas.

Enfim, acredita-se que há um vasto campo de estudo a ser percorrido na área e que existem lacunas a serem investigadas. Sendo assim, o presente trabalho instiga a realização de novas pesquisas que busquem enriquecer a literatura acerca do comprometimento organizacional e da gestão de pessoas, assim como da relação entre esses construtos.

\section{REFERÊNCIAS}

ALMEIDA, G. O. Quebra e violação do contrato psicológico: efeitos no comprometimento organizacional e na satisfação com o trabalho. In: ENCONTRO DA ASSOCIAÇÃO NACIONAL DE PÓS-GRADUAÇÃO E PESQUISA EM ADMINISTRAÇÃO, 33., 2009, São Paulo. Anais... São Paulo, 2009.

ANDRADE, T.; COSTA, V. F.; ESTIVALETE, V. F. B.; LENGLER, L. Comportamento de Cidadania Organizacional: Um Olhar à Luz dos Valores e da Satisfação no Trabalho. Revista Brasileira de Gestão de Negócios, v. 19, n. 64, p. 236-262, 2017.

ARRAES, V. M.; CABRAL, A. C. A.; SANTOS, S. M.; SILVA, M. N. M. Relação entre aspectos de modernidade organizacional e comprometimento organizacional. Revista de Administração Faces Journal, Belo Horizonte, v. 1, n. 16, p. 66-85, jan./mar. 2017. 
BALSAN, L. A. G.; COSTA, V. M. F.; BASTOS, A. V. B.; LOPES, L. F. D.; LIMA, M. P.; SANTOS, A. S. A influência do comprometimento, do entrincheiramento e do suporte à transferência de treinamento sobre o impacto do treinamento no trabalho. Revista de Administração da UFSM, Santa Maria, v. 10, n. 6, p. 976-989, 2017.

BASTOS, A. V. B. Comprometimento Organizacional: um balanço dos resultados e desafios que cercam essa tradição de pesquisa. Revista de Administração de Empresas, São Paulo, v.33, n. 3, p. 52-64, mai./jun. 1993.

BASTOS, A. V. B.; RODRIGUES, A. C. A.; MOSCON, D. C. B.; SILVA, E. E. C.; PINHO, A. P. M. Comprometimento no trabalho: fundamentos para a gestão de pessoas. In: BORGES, L.; MOURÃO, L. (Orgs.). $O$ trabalho e as organizações: atuações a partir da Psicologia. Porto Alegre: Artmed. 2013. p. 279-310.

BASTOS, A. V. B.; AGUIAR, C. V. N. Comprometimento Organizacional. In: PUENTE-PALACIOS, K.; PEIXOTO, A. L. A. (Org.). Ferramentas de diagnóstico para organizações e trabalho: Um olhar a partir da psicologia. Porto Alegre: Artmed, 2015. Cap. 5. p. 78-91.

BORGES, R. S. G.; MARQUES, A. L.; ADORNO, R. D. Investigando as relações entre políticas de $\mathrm{RH}$, comprometimento organizacional e satisfação no trabalho. In: ENCONTRO DA ASSOCIAÇÃO NACIONAL DE PÓS-GRADUAÇÃO E PESQUISA EM ADMINISTRAÇÃO, 29., 2005, Brasília. Anais... Brasília: ANPAD, 2005.

COSTA, L. V.; CHIUZI, R. M.; DUTRA, J. S. Relações entre percepção de sucesso na carreira e comprometimento organizacional: um estudo com professores do ensino superior de Administração. Revista de Administração da Unimep, v. 11, n. 2, p. 103-118, 2013.

DEMO, G. Desenvolvimento e validação da escala de percepção de políticas de gestão de pessoas (EPPGP). Revista de Administração Mackenzie, v. 9, n. 6, p. 77-101, 2008.

. Políticas de gestão de pessoas nas organizações: papel dos valores pessoais e da justiça organizacional. São Paulo: Atlas, 2010.

DEMO, G.; NEIVA, E. R.; NUNES, I.; ROZZET, K. Escala de políticas de recursos humanos: validação fatorial exploratória e confirmatória. In: DEMO, Gisela (Org.). Políticas de gestão de pessoas nas organizações: estado da arte, produção nacional, agenda de pesquisa, medidas e estudos relacionais. São Paulo: Atlas, 2012. Cap. 5. p. 96-117.

DEMO, G.; NUNES, I. Políticas de gestão de pessoas: pressupostos, definições, resultados e produção internacional recente. In: DEMO, Gisela (Org.). Políticas de gestão de pessoas nas organizações: estado da arte, produção nacional, agenda de pesquisa, medidas e estudos relacionais. São Paulo: Atlas, 2012. Cap. 2. p. 33-48. 
DEMO, G.; MARTINS, P. R.; ROURE, P. Políticas de gestão de pessoas, comprometimento organizacional e satisfação no trabalho na Livraria Cultura. Revista Alcance, v. 20, n. 2, p. 237254, 2013.

FERNANDES, C. M.; SIQUEIRA, M. M. M.; VIEIRA, A. M. Impacto da percepção de suporte organizacional sobre o comprometimento organizacional afetivo: o papel moderador da liderança. Revista Pensamento Contemporâneo em Administração, v. 8, n. 4, p. 140-162, 2014.

GIL, A. C. Como elaborar projetos de pesquisa. 5. ed. São Paulo: Atlas, 2010.

GROHMANN, M. Z.; CUNHA, L. V.; SILINSKE, J. Relações entre motivação, satisfação, comprometimento e desempenho no trabalho: estudo em um Hospital Público. In: ENCONTRO ACADÊMICO DE GESTÃO DE PESSOAS E RELAÇÕES DE TRABALHO DA ANPAD - EnGPR, 4., 2013, Brasília. Anais... Brasília: ANPAD, 2013.

HAIR JR., J. F.; BLACK, W. C.; BABIN, B. J.; ANDERSON, R. E.; TATHAM, R. L. Análise multivariada de dados. 6. ed. Porto Alegre: Bookman, 2009.

HENRIQUES, A.; SAWITZKI, R.; WEBER, T.; GARAY, A. Gestão de pessoas: desvendando a caixapreta em pleno vôo. GESTÃo.Org - Revista Eletrônica de Gestão Organizacional, v. 10, n. 2, p. 254-277, 2012.

HORTA, P.; DEMO, G.; ROURE, P. Políticas de gestão de pessoas, confiança e bem-estar: estudo em uma multinacional. Revista de Administração Contemporânea, v. 16, n. 4, p. 566-585, 2012.

IRIGARAY, H. A.; OLIVEIRA, L.; BARBOSA, E.; MORIN, E. Vínculos Profissionais e Sentido do Trabalho: Uma Pesquisa com Professores do Ensino Superior. Revista de Administração Mackenzie, v. 20, n. 1, p. 1-27, 2019.

JESUS, R. G.; ROWE, D. E. O. Comprometimento Organizacional: Tradução, Adaptação e Validação para o Contexto Brasileiro da Escala de Sacrifícios Percebidos Associados com a Saída. In: ENCONTRO DE ESTUDOS ORGANIZACIONAIS DA ANPAD - EnEO, 8., 2014, Gramado, RS. Anais... Gramado, 2014.

Adaptation and obtainment of evidence for the validity of the "Scale of Perceived Sacrifices Associated with Leaving (the organization)" in the Brazilian context: a study among teachers of basic, technical, and technological education. Revista de Administração USP, v.52, p. 93-102, 2017.

JESUS, R. G. Comprometimento organizacional: um estudo de suas relações com percepção de gestão de pessoas e percepção de justiça organizacional. 2016. 378 f. Tese (Doutorado) - Curso de Administração, Escola de Administração, Universidade Federal da Bahia, Salvador, 2016. 
LEITE, N. P.; ALBUQUERQUE, L. G. Gestão estratégica de pessoas, comprometimento e contrato psicológico: o caso Vale. Revista de Administração, v. 46, n.1, p. 19-31, 2011.

. Gestão estratégica de pessoas, estratégia de retenção de profissionais e comprometimento organizacional em uma estrutura organizacional remota. Revista de Administração da UFSM, v.6, n. 4, p. 803-822, dez. 2013.

LEITE, A. M. A. A.; FERREIRA FILHO, J.; CABRAL, A. C. A.; SANTOS, S. M.; PESSOA, M. N. M. Visão compartilhada e comprometimento organizacional: um estudo de caso na EMBRACON Empresa Brasileira de Consórcios. Revista de Administração da UFSM, Santa Maria, v. 8, n. 3, p. 482-498, jul./set. 2015.

LIMA, C.C.A; ROWE, D.E.O. Gestão de Pessoas e Comprometimento Organizacional: artigos publicados entre 2004 e 2013. In: Seminários em Administração - SEMEAD, 17., 2014, São Paulo, SP. Anais... São Paulo, 2014.

LÍRIO, A. B.; SEVERO, E. A.; GUIMARÃES, J. C. F. A influência da qualidade de vida no trabalho sobre o comprometimento organizacional. Revista Gestão e Planejamento, Salvador, v. 19, p. 34-54, jan./dez. 2018.

MALHOTRA, N. K. Pesquisa de marketing: uma orientação aplicada. 6. ed. Porto Alegre: Bookman, 2012.

MARIANO, T. L. A. B.; MOSCON, D. C. B. As relações entre as práticas de gestão de pessoas e o desenvolvimento de vínculos com a organização: um estudo em uma empresa de contabilidade. Revista Gestão e Planejamento, Salvador, v. 19, p. 227-243, jan./dez. 2018.

MEYER, J. P.; ALLEN, N.J. A three-component conceptualization of organizational commitment. Human Resource Management Review, v. 1, n. 1, p. 61-89, 1991.

MEYER, J. P.; ALLEN, N. J.; SMITH, C. A. Commitment to organizations and occupations: extension and test of a three-component conceptualization. Journal of Applied Psychology, v. 78, n. 4, p. 538-551, 1993.

MILHOME, J. C.; ROWE, D. E. O.; SANTOS, M. G. Existem relações entre qualidade de vida no trabalho, comprometimento organizacional e entrincheiramento organizacional? Contextus: Revista Contemporânea de Economia e Gestão, Fortaleza, v. 16, n. 3, p. 232-252, set./dez. 2018.

OLIVEIRA, M. J. L.; CABRAL, A. C. A.; PESSOA, M. N. M.; SANTOS, S. M.; ROLDAN, V. P. S. Comprometimento organizacional e regime de remuneração: estudo em uma carreira pública de auditoria fiscal. RAM - Revista de Administração Mackenzie, São Paulo, v. 15, n. 5, p. 72-101, out. 2014. 
PILATI, R.; BORGES-ANDRADE, J. E. Comprometimento no trabalho, motivação e estratégias de aplicação como preditores de efetividade de treinamento. In: ENCONTRO DA ASSOCIAÇÃO NACIONAL DE PÓS-GRADUAÇÃO E PESQUISA EM ADMINISTRAÇÃO, 29., 2005, Brasília. Anais... Brasília, 2005.

PILATI, R.; LAROS, J. A. Modelos de equações estruturais em psicologia: conceitos e aplicações. Psicologia: Teoria e Pesquisa, v. 23, n. 2, p. 205-216, 2007.

POLIZZI FILHO, A.; CLARO, J. O Impacto de Bem-Estar no Trabalho e Capital Psicológico sobre Intenção de Rotatividade: Um Estudo com Professores. Revista de Administração Mackenzie, v. 20, n. 2, p. 1-27, 2019.

POWELL, D. M.; MEYER, J. P. Side-bet theory and the three-component model of organizational commitmet. Journal of Vocational Behavior, v. 65, p. 157-177, 2004.

REIS NETO, M. T.; MARQUES, E. R. C.; PAIVA, R. Integração entre valores, motivação, comprometimento, recompensas e desempenho no serviço público. Revista Eletrônica de Estratégia \& Negócios, Florianópolis, v. 10, n. 1, p. 3-39, abr. 2017.

RIBEIRO, J. A. Comprometimento Organizacional e Percepção de Justiça: um estudo sobre a concessão de remuneração e benefícios diferenciados a dois grupos de uma mesma empresa. In: ENCONTRO DA ASSOCIAÇÃO NACIONAL DE PÓS-GRADUAÇÃO E PESQUISA EM ADMINISTRAÇÃO, 32., 2008, Rio de Janeiro, 2008. Anais... Rio de Janeiro: ANPAD, 2008.

RIBEIRO FILHO, J. G.; HONÓRIO, L. C. Comprometimento organizacional: comparando docentes efetivos e temporários de uma Instituição de Ensino Superior. Revista Organizações em Contexto, v. 10, n. 20, p. 173-204, 2014.

ROMAN, S.; STEFANO, S. R.; ANDRADE, S. M.; ZAMPIER, M. A. Análise do comprometimento organizacional e sua natureza em relação aos funcionários públicos municipais. Gestão \& Regionalidade, v. 28, n. 84, p. 5-19, 2012.

ROWE, D. E. O. Múltiplos comprometimentos e suas relações com o desempenho: um estudo entre docentes do ensino superior brasileiro em IES públicas e privadas. 2008. Tese (Doutorado em Administração). Escola de Administração. Universidade Federal da Bahia, Salvador, 2008.

ROWE, D. E. O.; BASTOS, A. V. B.; PINHO, A. P. M. Múltiplos comprometimentos com o trabalho e suas influências no desempenho: um estudo entre professores do ensino superior no Brasil. Organizações \& Sociedade, v. 20, n. 66, p. 501-521, 2013.

SANTOS, M. S. C.; ANDRADE, A. F.; SOUSA, A. S.; MOREIRA, I. O. Comportamento organizacional: um estudo sobre o comprometimento organizacional numa empresa de material de construção. Revista RaUnP, Natal, v. 8, n. 2, p. 20-33, maio 2016. 
SANTOS FILHO, G. M.; MOURÃO, L. Relação entre comprometimento organizacional e impacto do treinamento no trabalho. Revista Psicologia, Organizações e Trabalho, v. 11, n. 1, p. 75-89, 2011.

SCHIRRMEISTER, R.; LIMONGI-FRANÇA, A. C. A qualidade de vida no trabalho: relações com o comprometimento organizacional nas equipes multicontratuais. Revista Psicologia, Organizações e Trabalho, Florianópolis, v. 12, n. 3, p. 283-298, dez. 2012.

SILVA, C. C.; LEITE, N. R. P.; RODRIGUES, L. C. Gestão estratégica de pessoas e comprometimento organizacional em organizações hospitalares. Revista de Administração da UFSM, Santa Maria, v. 9, n. 2, p.192-209, abr./jun. 2016.

SILVA, C. S. S.; PINTO, C. C.; MOURA, H. N.; ARANTES, B. O. O papel da "avaliação de desempenho por competências" no estado de Minas Gerais segundo a perspectiva dos servidores públicos estaduais. Caderno Profissional de Administração - Unimep, Piracicaba, v. 8, n. 1, p. 69-90, 2018.

SILVA, R. C. D.; TOMAZZONI, G. C.; COSTA, V. M. F. Comprometimento e entrincheiramento organizacionais: uma análise comparativa com duas instituições de ensino superior. Revista Gestão.Org, Recife, v. 16, n. 1, p. 57-68, 2018.

SIQUEIRA, M. M. M.; GOMIDE JÚNIOR, S. Vínculos do indivíduo com o trabalho e com a organização. In: ZANELLI, J. C.; BORGES-ANDRADE, J. E. e BASTOS, A. V. B. (Orgs.). Psicologia, Organizações e Trabalho no Brasil. Porto Alegre: Artmed, 2004.

SOBRINHO, J. M.; SILVA, A. P. A administração pública gerencial e seus reflexos nas práticas e políticas de treinamento na prefeitura de Damião - PB. Sinergia: Revista do Instituto de Ciências Econômicas, Administrativas e Contábeis, Rio Grande, v. 19, n. 1, p. 21-32, 2015.

SOUZA, E. P.; MARQUES, A. L. Práticas de recursos humanos e comprometimento organizacional: considerações teóricas sobre como o comprometimento pode ser tratado nas organizações. In: ENCONTRO DE ESTUDOS ORGANIZACIONAIS DA ANPAD - EnEO, 8., 2014, Gramado. Anais... Gramado, 2014.

TINTI, J. A.; COSTA, L. V.; VIEIRA, A. M.; CAPPELLOZZA, A. O Impacto das Políticas e Práticas de Recursos Humanos Sobre os Comportamentos de Cidadania Organizacional. Brazilian Business Review, v. 14, n. 6, p. 636-653, 2017.

VENTURA, V. L. S. A percepção da influência da gestão estratégica de pessoas no comprometimento organizacional pelos docentes do ensino superior. 2012. Tese (Doutorado em Administração). Universidade Nove de Julho - UNINOVE, São Paulo, 2012.

VENTURA, V. L. S.; LEITE, N. R. P. Percepção da influência da gestão estratégica de pessoas no comprometimento organizacional. Pretexto, Belo Horizonte, v. 15, n. 3, p. 11-28, jul./set. 2014. 